\title{
Tracing the Desire and Lack on Semiotic Landscape of a Daniel Garcia Art: Your Own Personal Slaves
}

\author{
Yohanes Padmo Adi Nugroho ${ }^{1}$, Eri Susanto ${ }^{2}$ \\ \{padmoadi@ub.ac.id ${ }^{1}$, eri.susanto@ub.ac.id ${ }^{2}$ \} \\ Universitas Brawijaya, Indonesia ${ }^{1,2}$
}

\begin{abstract}
Your Own Personal Slaves is an artwork made by Daniel Garcia. This research tries to answer three status questions upon the artwork: a) Is this art merely a symptomatic hysteria of the oppressed condition? b) Does this art success to be the sublimation, a jouissance? c) Can this art let the subaltern speak? The art is uploaded on Garcia's website, Instagram, and Facebook. There are two versions of this title: 2016 version and 2018 version. This research is conducted with qualitative method in order to describe the artwork by Daniel Garcia entitled Your Own Personal Slaves (2016) used as data in the theoretical framework of semiotics and psychoanalysis. This research would trace the desire and lack, in the paradigm of lacanian psychoanalysis. The research results that we see the irony depicted on this art. The tears she holds make her seems have kind of empathy toward the people in suffer. The Che Guevara shirt shows us as if she is a leftist who will fight against any oppression. Yet, she herself sits upon all of these oppressions, so comfortably that she had her white bourgeois supremacies privilege.
\end{abstract}

Keywords: Psychoanalysis, Desire, Lack, Semiotic, Subaltern

\section{Introduction}

Daniel Garcia is an editorial illustrator focusing on political and social issues, with work published in more than 15 countries around the world [1]. His website is https://www.danielgarciaart.com. We can also find his art activity on his Instagram account, (a)daniel_garcia art. Most of his art is an ironic and a cynic. Some of them are commission, usually for a cover of some magazines. His paintings are illustration, painting, design on social, political and human issues [2]. His arts are represented in the U.S. by Spinning Yarn, on www.spinningyarnreps.com. From all of his arts, there is one art that draws our attention, it is titled Your Own Personal Slaves. There are two versions of this art, 2016 version and 2018 version. The 2018 version is an adaptation of the 2016 version for a book cover of Markus Szaszka book titled "Nirgensmann" (Nowhere Man), so we do not pick that version, even though the 2018 is also interesting. We are focusing on the 2016 ones. 


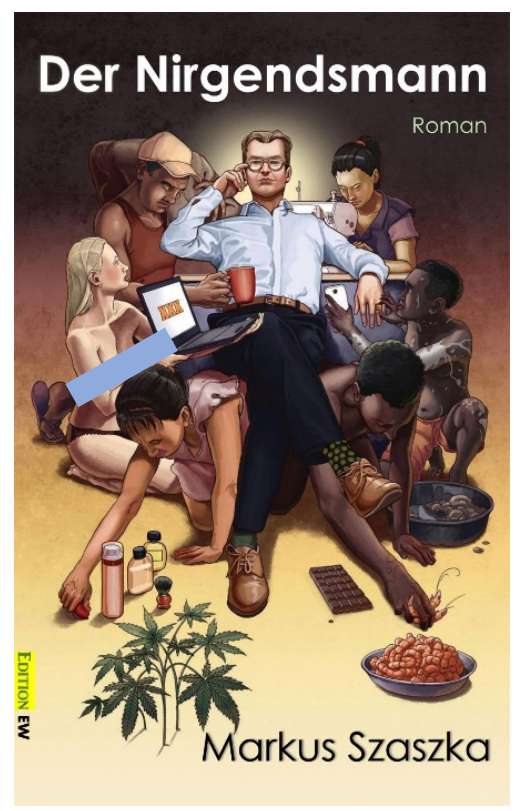

Fig. 1. This is 2018 version, an adaptation from 2016 version. It is for Markus Szaszka's cover book.

Your Own Personal Slaves by Daniel Garcia depicts a white woman sitting comfortably while she holds her tears. She wears a black t-shirt with silhouette of Che Guevara's face. She is surrounded by six people: three females and three males. The six are from various identity: white, Latin-American, Asian, and African. All of the six are depicted serving the main character with all of things to fulfil her needs. The white girl serves the porn videos, the LatinAmerican man serves a cup of coffee, the Asian maiden serves her fabrics, one of the African serves her with coltan ${ }^{1}$ so that her smartphone battery can run well, while the other African man serves chocolate and shrimps, and the one girl serves her the makeup cosmetic tools. There are also some marijuana trees there. The main character sits on them.

The picture is indeed provoking. It criticizes precisely on the point of when capitalism works, but it doesn't work for all of us, yet only for a few privileged people; and even though they put their empathy on the oppressed people, they still enjoy that very privilege. Is this art merely a symptomatic hysteria of the oppressed condition? Does this art success to be the sublimation, a jouissance? Can this art let the subaltern speak? From this point, we would like to trace the desire and lack, in the paradigm of lacanian psychoanalysis. But, before we do that, we will slice aspect per aspect on the semiotic level.

Concerning previous study about lacanian theory over artwork, we faced difficulties to find them. As a matter of comparison, Pappas [3] has discussed about film and psychoanalysis and Brockelman [4] has shown Lacan's contrast between the definition of a painting as a

\footnotetext{
${ }^{1}$ In the website Garcia mentions coltan, not cobalt; both are needed to make battery. Therefore, we follow the thing Garcia mentions: coltan. Cf. Daniel Garcia, Your Own Personal Slaves, 2016, on http://www.danielgarciaart.com/yourown-personal-slaves/, accessed March 21, 2021. Cf. Todd C. Frankel, THE COBALT PIPELINE, Tracing the path from deadly hand-dug mines in Congo to consumers' phones and laptops, September 30, 2016, on https://www.washingtonpost.com/graphics/business/batteries/congo-cobalt-mining-for-lithium-ion-battery/, accessed March 21, 2021.
} 
"window" and Foucault's implicit understanding of it as a kind of "mirror"- a distinction in which Lacan discovers his seminal concept of "objet a".

\section{Research Method}

This research is conducted with qualitative method in order to describe the artwork by Daniel Garcia entitled Your Own Personal Slaves (2016) used as data in the theoretical framework of semiotics and psychoanalysis. As mentioned on introduction, this research would trace the desire and lack, in the paradigm of lacanian psychoanalysis.

The main source of this research is Daniel Garcia's painting titled Your Own Personal Slaves. It is on his social media account. The one we downloaded was from his Instagram. First, we use semiotics approaching to analyze the drawing. We see the drawing as it is holistically. After that, we mutilate the drawing according to its element, signifier per signifier. Then we analyze those signifiers one by one.

After we are done with semiotics analysis, we begin to use lacanian psychoanalysis. In every signifier we use in language, there must be trace of desire. We trace those desires start from every signifiers Garcia presents us. We are looking for symptoms there, or maybe those symptoms have been glorified to become synthome ${ }^{2}$.

We use Lacan's concept of Four Discourses, especially the Discourse of the Analyst, to elaborate the analysis and to trace the objet petit $a$. The first discourse is the Discourse of the Master; it is the primary discourse. Then there are Discourse of the University, Discourse of the Analyst, and Discourse of the Hysteric. The Discourse of the Master is "[...] the primary genre of discourse, while the other discursive genre can be regarded as efforts to dethrone or escape from the tyranny of the Master (S1)" [5].

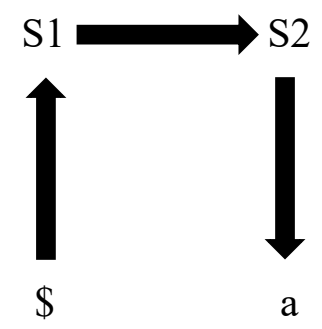

\subsection{The Structure of the Discourse of the Master}

S1 here is the agent, the Master, who gives order to S2 to work. While the truth of the Master is the divided Subject (\$). The product of this structure is objet petit a, the desire. This kind of discourse is being used in the grand narrative, law, moral ethics, religion, and many other languages from the Master. The subject using this discourse has only two option: yes or no, agree or disagree, incorporated or separated, life or death. All the other three discourses are being used to dethrone this discourse. The Discourse of the University is being used by the

\footnotetext{
${ }^{2}$ Synthome is born and is emancipated from the symptom. In another word, sinthome is symptom which has been realized and being used on purpose. Cf. Jean Allouch, Where There is Symptom and Sinthome, on http://www.jeanallouch.com/pdf/350, accessed December 15, 2020.
} 
scientists. While the Discourse of the Analyst is often being used by artists. The Discourse of the Hysteric is being used by the victims.

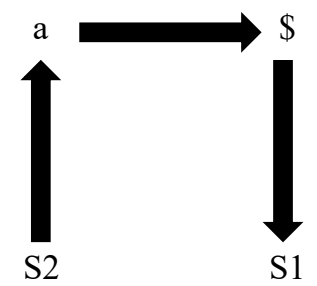

\subsection{The Structure of the Discourse of the Analyst}

In this research, we will focus on the Discourse of the Analyst, because we want to trace the desire, the objet petit $a$, in the Garcia's drawing. We will see that it is the desire which speaks and criticize the sublime grand narrative. The truth behind the petit $a$ is the Discourse of the University (S2). This Analyst Discourse reveals the lack of the subject.

\section{Result and Discussion}

\subsection{Semiotic Landscape}

Semiotic landscape [6] refers to visual communication of society in terms of range of forms or modes through its uses, functions, and valuations, such as metaphor/style, history/diachrony, culture/dialect, society/economy. Semiotic modes involve the intrinsic characteristics and potentialities of the medium and by the requirements, histories and values of societies and their cultures.

In 2011, Slavery Footprint launched a website that asked a single question: "How Many Slaves Work for You?" Then in 2016, Garcia immortalize this phenomenon under the form of illustration art baptized with similar question "How many slaves do you have working for you?"

Here we made the classification of hashtags and tags for the semiotic landscape of the art Your Own Personal Slaves. Slavery or forced labor [7] is anyone who is forced to work without pay, being economically exploited, and is unable to walk away.

Garcia would invite us as consumer to take in a count our consumption that could lead to modern slavery. To illustrate, Slavery Footprint [7] warns us how slave labor work for our consumption. This supply chain enslaves more people than at any other time in history.

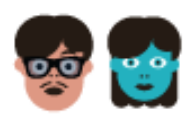

You \& Me

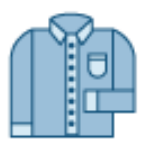

Brand

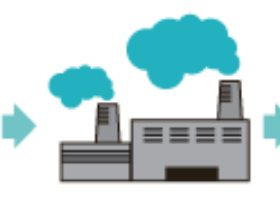

Manufacturer

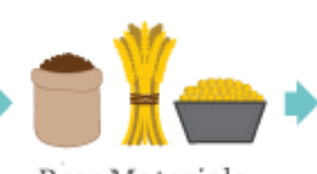

Raw Materials

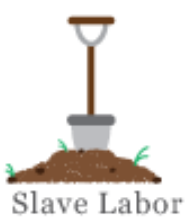

We use the 2016 version instead because this one is the "original" version of the title and the main character of this art is more interesting than the adaptation version, which is a white 
man in white collar shirt. The 2016 version depicts a white woman, in black t-shirt with the silhouette of Che Guevara's face, sitting comfortably, holding her tears, while being served by many slaves: a white pornstar girl serves her with sex-tertainment, Latin-American man serves her with a cup of coffee, a Asian maiden serves her with the fabric she might wear, an African boy - a miner serves her the best coltan for her lithium smartphone battery, an African man serves her with shrimps and chocolate, and a girl serves her with the best makeup cosmetic tools possible. The woman, the main character, sits upon all of them. Let us see comprehensively the picture itself.

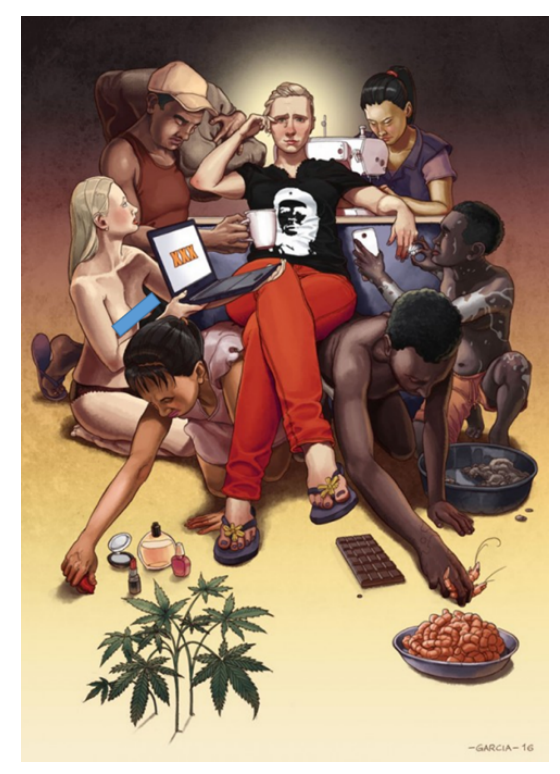

Fig. 2. Your Own Personal Slaves by Daniel Garcia, 2016.

(c) Daniel Garcia 2016.

Tags: cannabis, chocolate, coffee, coltane, editorial, fashion, food, makeup, man, palm oil, porn, slaves, smartphone, sweat shops, woman [8]

\#shopping \#discount \#girl \#capitalism \#food \#informatic \#coffee \#childlabor \#cosmetics \#clothes \#poverty \#smartphone \#ring \#pc \#sweatshop \#food \#slavery \#art \#artwork \#artdirector \#illustrationart \#illustration \#editorialillustration \#cartoon \#creative \#color \#drawing \#dibujo \#comics \#satirical [9]

We see irony of a white leftist woman with her sym-pathetic tears, sitting upon oppressed people. We would like to trace this irony. The irony here was born from the desire and the lack of a subject, in this case is the main character of the art. We would like to trace this desire and lack using lacanian psychoanalysis theory. But, before we went further with psychoanalysis, we will analyze the art with the method of semiotics. From that method, we will see that this main character is the lack subject, the divided subject. And, we will also see that this art reveals the subaltern people we hardly to see in our daily life. This art does not only show the divided subject of privileged white woman, but also speaks louder for the subaltern people around the world. 
Now, we analyze part by part of this drawing. Hashtags and tags help us to identify or recognize the commodity we consume and its implication about modern slavery in sweat shops; a poor, illegal, or unacceptable workplace. Garcia used different appeal words through Instagram and his website. Here's the connection of semiotic landscape and the data according to ilo.org (2017) and slaveryfootprint.org (2011):

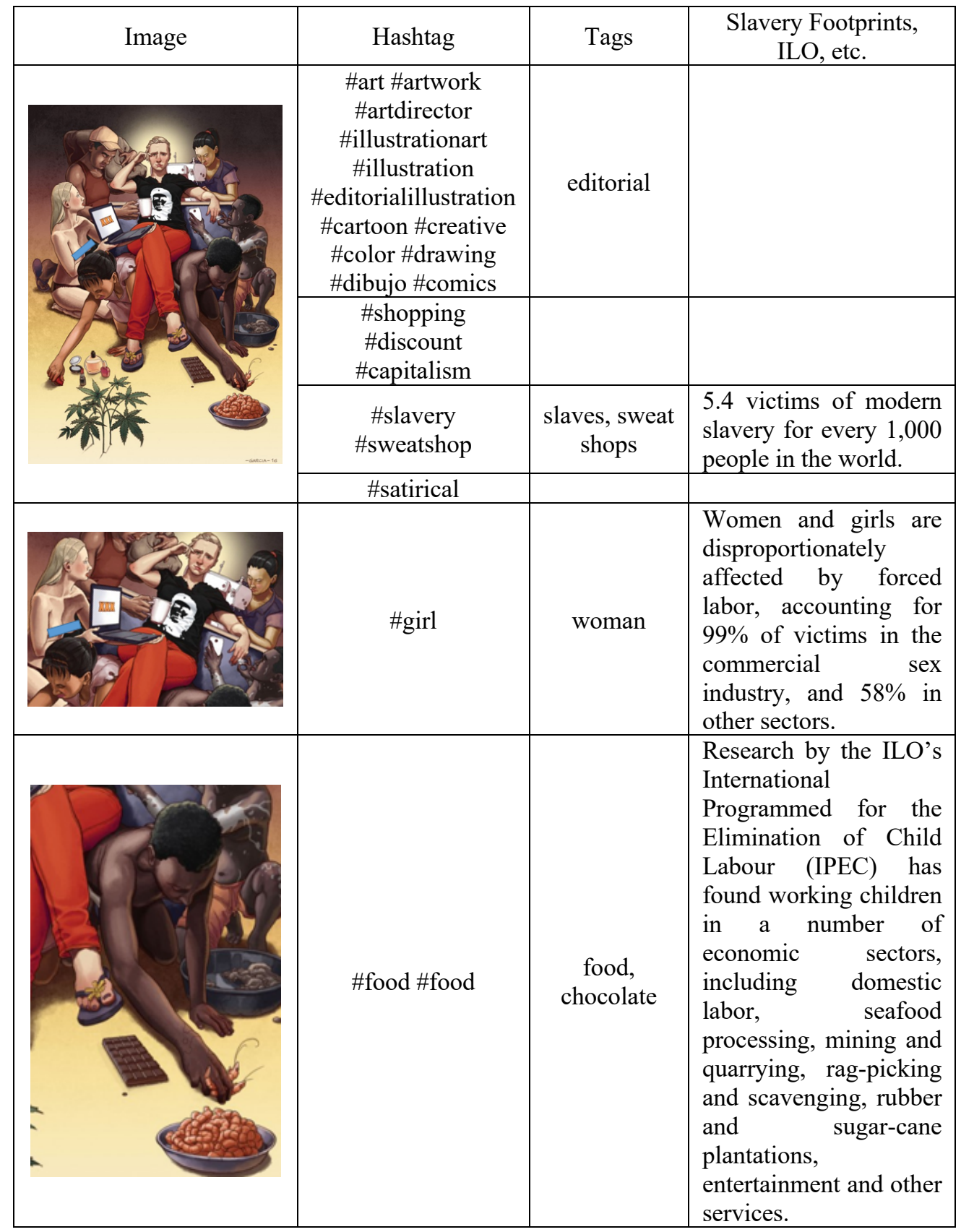




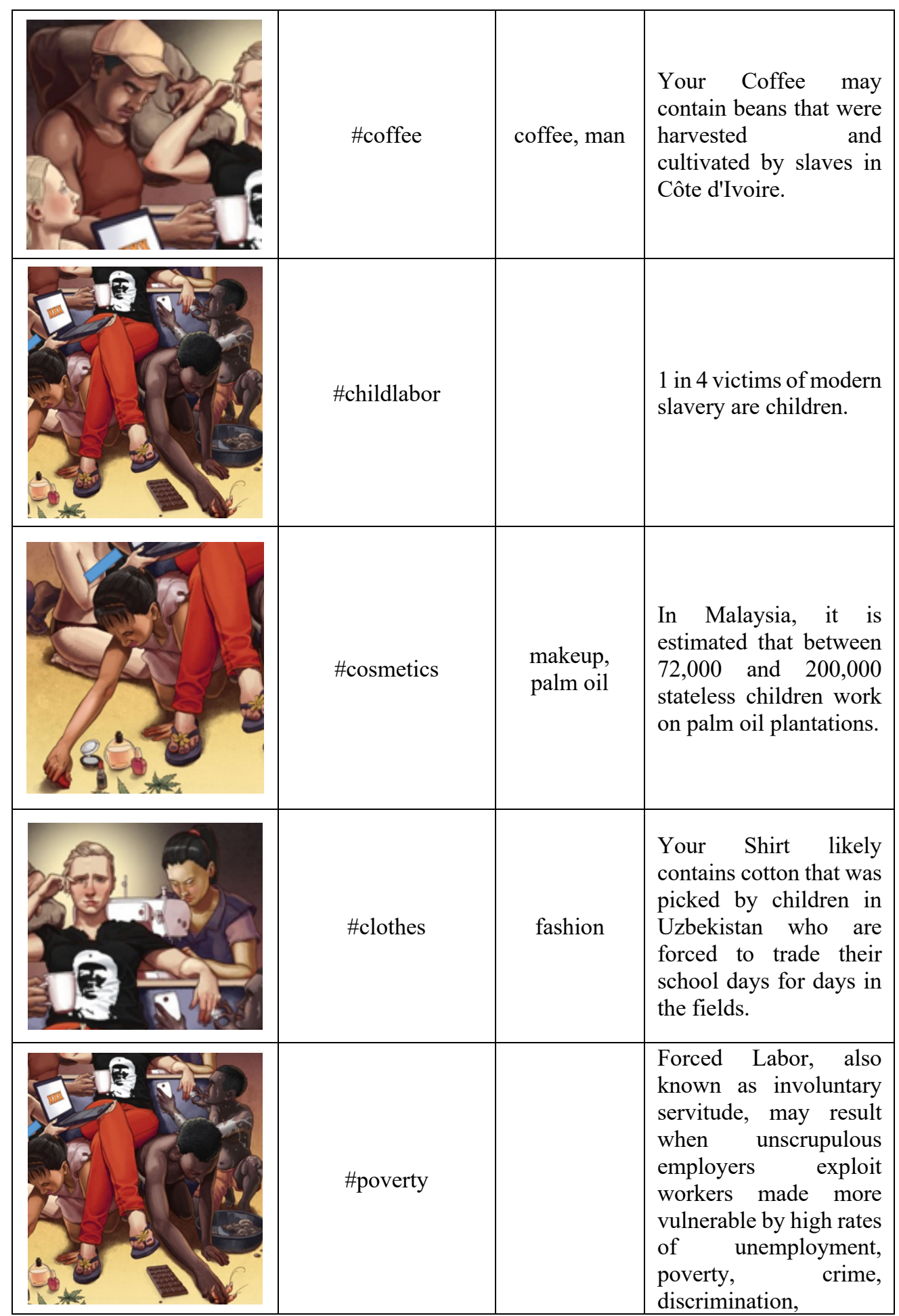




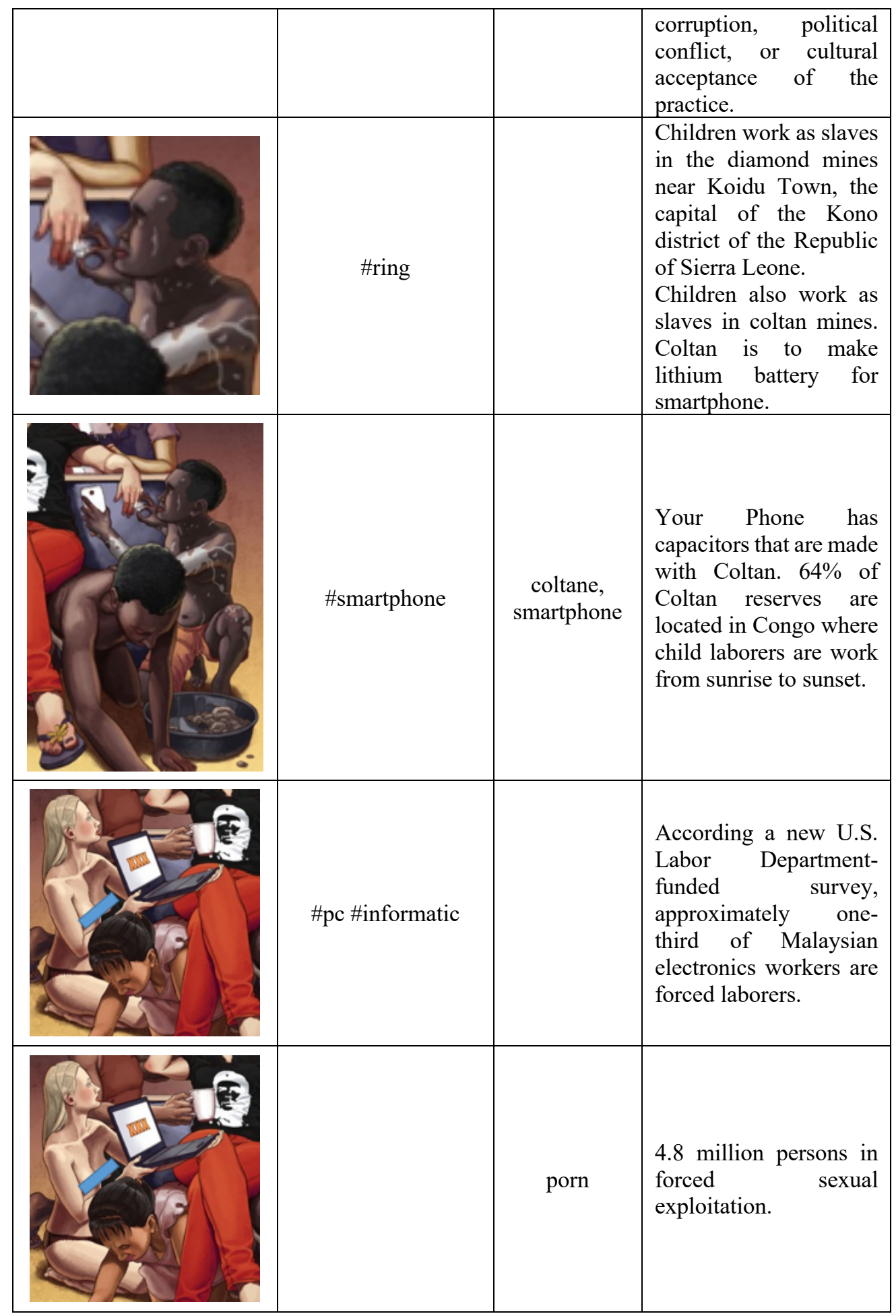




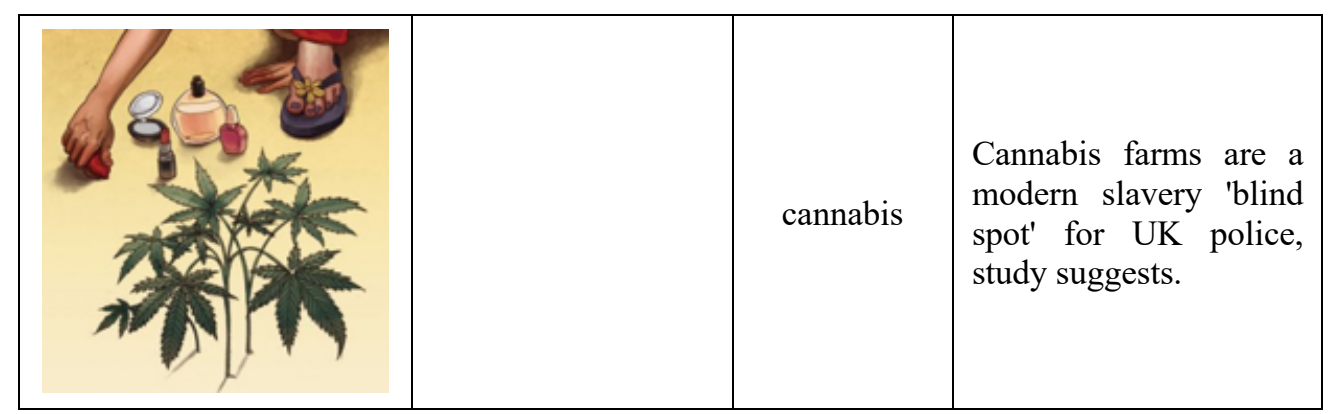

\subsection{Traces of the Desire}

After we slice part by part, aspect by aspect, using semiotic approach, now we will see those parts using the paradigm of lacanian psychoanalysis. "The unconscious is structured like a language," said Lacan [10]. Here we can know that Lacan not only wanted to return to Freud, but also took the perspective of Linguistics. The structured unconscious like a language is the center of Lacan's theory and maybe his fundamental contribution to psychoanalysis. We are only able to know the unconscious merely and only by language, the speech, the signifier. There are always traces of the desire the time we use the language. Therefore, we can trace the desire and lack of Your Own Personal Slaves.

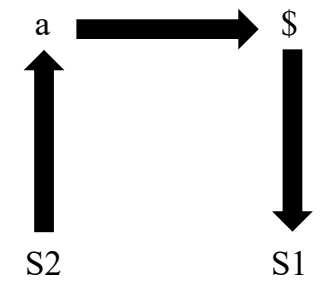

All the signifiers used by Garcia have the trace of the desire. We can put those signifiers in the position of the petit a (desire). The structure of the Discourse of the Analyst let us see that all of the $a$ 's depicted by Garcia there lead us to the reality of the lack Subject. We will see those $a$ 's from the semiotics point of view. We now know that Your Own Personal Slaves speaks about modern slavery, violence against women, child labor, low wage labor, and the controversy of cannabis. We see a lot of objet petit a (the unattainable object of desire) there. Objet petit a is any object that makes you remember the desire after the castration. It is object of rem(a)inder; it reminds you of your remainder. What remainder it reminds? Everything of you that cannot be spoken to language, because the Symbolic (language itself, rules, laws, society, the Father) forbids. Objet petit $a$ is like $x$ in mathematics; it is there, yet we must find, and when we think we have found, it is no longer there. Objet petit a can be anything. In this case, it is on the visual, on the Gaze. Objet petit $a$ is on the drawing of the woman and her tears. It is on the Che Guevara t-shirt she wears. It is on the food, shrimps, and chocolate, as well as on the African man who collects them. It is on the cup of coffee the man brings. It is on the child labor in Africa, who mine coltan. It is on the white smartphone the child labor provides. It is on the cosmetics. It is on the clothes made by Asian low wage labor. It is on the young naked pornstar who provide audio-visual sex-tertainment. Moreover, it is on the controversial cannabis. 
Those things we mention above is symptomatic Signifier. On the level of semiotics, we see that all of the things mention above has its own problematic existence. In the level of Symbolic, we hardly know that they even existed. They are silenced. We may not discuss about pornographic labor in the bright day light. Moreover, discussing sex is taboo for some society, let alone people who are forced to labor in that field. Yet, Daniel Garcia depicts her as a topless innocent girl who willingly provide the main character some sex-tertainment she needs. Even though the pornstar girl and the main character are all white, seems that they are still from different social status. People who know Che Guevara must know the ideology he lived; therefore, they are well educated people. Educated people of course is considered honored middle class alias bourgeois. Daniel Garcia does not depict the pornstar girl merely as a sex object, like in the many porn movie, yet he sublimes her gesture. The girl gesture is a gesture of blowjob scene, yet Daniel Garcia draws it someway that the girl looks like willingly to serve the main character her videos. Although she is there as pornstar, Daniel Garcia does not draw her vulgar, yet he uses the legendary gesture so that the girl seems to be able to speak for herself.

Another silenced Signifier is the man who serves the main character with a glass of coffee. Who does not like coffee? Who drinks coffee every day? Almost all of us drink coffee, at least we have ever tried before. Some of us drink coffee on regular basis. But we never ask where does our coffee been come from. In this picture, Daniel Garcia seems like telling us, who cultivates the soil and brings the finest coffee been to us, that we can enjoy our morning or our orange twilight. He does not depict the person in protest or in angry gesture, instead he draws him so gently serving a cup of coffee as if it is a mockery to us who do not know whoever behind our daily cup of coffee. Suddenly, our Signified of coffee- orange twilight, broken into pieces.

This Daniel Garcia's drawing show us child labor. This child labor is low wage, even they are enslaved. They are forced to work by one or many reasons so that they can have something for survive, while we can have our smartphone works well. Behind our sophisticated gadget, there are lots of child labor work in mine. Of course, this reality is almost unspoken. How on earth can we understand that our smartphone lithium battery is provided in front of us by this child labor? The African child labor is drawn so gladly giving the smartphone and the gem to the main character.

The center of this picture is of course the white woman in black Che Guevara t-shirt. She is depicted having tears as if she gives her sympathy to the oppressed subalterns. She wears Che Guevara; as we know, he is the symbol of anti-colonialism, anti-imperialism, and a hero of some leftist. Here Daniel Garcia sublimely shows us the irony. Even the leftist white woman who seems give sympathy to the oppressed subaltern is indeed also the one who sits comfortably upon the oppressed themselves. Doesn't matter how leftist you are, how feminist you are, or how humanist you are, as long as you are the middle-class white people, you still got and enjoyed the privilege brought to you by the centuries (post-)colonialism. Nevertheless, facing this picture, it is like facing through a window. When we see through the eyes of the main character woman, seems that we see ourselves beyond that window; that the woman become I. We are pushed to the Symbolic of this picture. We must face the Signifiers one by one. It makes the I split. We become fractured Subject (Lacan use the symbol \$ to describe this split subject). On our computer we work with, our smartphone we are connected with, our culinary we eat and drink, our fashion wear, there are sufferings. We think we do not do that, especially if we are not white. That is not us. Yet, we indeed enjoy the same privilege. 
Facing the picture, we are driven to the exact desires of us. We, as a subject, desperately seek the desire ourselves $(\$<>a)^{3}$. Then we realize that our world is not alright as we thought it were. The art fills us with this emptiness. What we can do with those enslaved?

Actually, all of the slaves depicted there by Daniel Garcia are horrifying. We know they are suffering even though Daniel Garcia does not draw the expression of pain. Nevertheless, we see them looks like doing their things sincerely and steadfast. Daniel Garcia plays with these Signifiers. He puts the symptoms to the lap of das Ding that they become synthome. They show pain without depict any pain. They show oppression without fall into hysteria anger. Daniel Garcia lets the oppressed/the subaltern speaks, not in an anger, but in the most splendid way possible. This is art about protest and critic, yet there is no anger and there is no hysteria here, instead synthome [11]. This art gives us void who sucks us to the unspoken ugly truth about modern slavery in the name of civilization progress (technology, fashion, culinary, etc.). This art makes us sick, make us split. This art makes us realize that the world we live and the privilege we have is not there alright. This art moves us. First, it moves our cognitive. Second, it moves our emotion. Third, it may move our body to do something!

\section{Conclusion}

Daniel Garcia's art titled Your Own Personal Slaves is indeed a sublime art that depicts and criticize oppression without fall into a hysterical amok. The artist shows us the suffering without dramatizing that suffering, yet he shows cynicism. Cynicism is the way we can deal with very bitter reality. Therefore, he lets all the oppressed subject, the subaltern, speaks for themselves; their sincerity depicted on the drawings sue our sanity. This is a window to us to see, that we are part of the main character that enjoys every privilege we get from that very oppression. We see that Thing, a void that sucks our existence, that after we see this drawing, we would see our daily world and its civilization (entertainment, culinary, fashion, etc.) in the new perspective, a perceptive which makes us aware that we are not that alright and must do something about it. We see an irony we are living in; the irony depicted on this art speaks for itself, that we see our ugly truth. The modern life we live, however modest or leftist, will always need the silent slaves. Yet, there is still a question to be answered: how we can alternate this kind of reality or let us surrender to this structured symbolic order? We need to discuss further about the Fantasy.

\section{References}

[1] Daniel Garcia, "Daniel Garcia Facebook," Daniel Garcia, 2016. [Online]. Available: https://www.facebook.com/danielgarciaart/photos/1162351310523840/.

[2] Daniel Garcia, "Daniel Garcia Facebook," Daniel Garcia. [Online]. Available: https://www.facebook.com/danielgarciaart/about/?ref=page_internal.

[3] N. Pappas, "Psychoanalysis and the Philosophy of Film," in The Palgrave Handbook of the Philosophy of Film and Motion Pictures, Springer, 2019, pp. 923-945.

[4] T. Brockelman, "The other side of the canvas: Lacan flips Foucault over Velázquez," Cont. Philos. Rev., vol. 46, no. 2, pp. 271-290, 2013.

[5] H. Zwart, Tales of research misconduct: A Lacanian diagnostics of integrity challenges in science novels. Springer Nature, 2017.

${ }^{3}(\$<>$ a) is the structure of Fantasy. 
[6] G. Kress and T. Van Leeuwen, Reading images. Deakin University Press Geelong, 1990.

[7] Slavery Footprint, "Slavery Footprint," Slavery Footprint, 2020. [Online]. Available: https://slaveryfootprint.org/.

[8] D. Garcia, "Daniel Garcia Art. Retrieved from Daniel," Garcia Art, 2020. [Online]. Available: https://www.danielgarciaart.com/your-own-personal-slaves/.

[9] D. Garcia, "Daniel Garcia Art," Daniel Garcia Art, 2020. [Online]. Available: https://www.instagram.com/p/BhYj_sQBPbM/.

[10] J. Gasperoni, "The unconscious is structured like a language," Qui Parle, pp. 77-104, 1996.

[11] St. Sunardi, "In seminar of Seni sebagai Peristiwa Pengalaman Indonesia 20 Tahun Terakhir," Salihara Arts Center YouTube Channel, 2013. [Online]. Available: https://www.youtube.com/watch?v=9-CI3prsF5g\&t=610s . 